\title{
VIDA E TRABALHO DOS CORTADORES DE CANA: MIGRAÇÃO, ASSALARIAMENTO TEMPORÁRIO E LABOR NOS CANAVIAIS PAULISTAS
}

\author{
LIFE AND WORK OF SUGAR CANE CUTTERS: \\ MIGRATION, TEMPORARY WORK AND LABOUR IN \\ SÃO PAULO'S SUGAR PLANTATION
}

Juliana Biondi Guanais ${ }^{1}$

RESUMO: O objetivo do presente artigo é analisar alguns aspectos gerais das condições de vida e de trabalho dos cortadores de cana brasileiros. Para tanto, este trabalho foi dividido em duas partes. Na primeira, será discutido quem são, de onde partem e quais os motivos que levam esses trabalhadores a buscarem emprego nas diversas usinas de açúcar e álcool do país. Essa primeira parte é necessária para que se possa deixar claro a importância desse assalariamento temporário e da renda obtida por seu intermédio para os trabalhadores rurais e suas famílias. Já na segunda parte, serão apresentadas as condições de trabalho dos cortadores de cana e, para tanto, serão analisadas algumas das principais estratégias empregadas pelos representantes do setor sucroalcooleiro. Este artigo se baseia nas pesquisas realizadas junto à Usina Ester e à Usina Costa Pinto (localizadas, respectivamente, em Cosmópolis e Piracicaba, interior de São Paulo) e seus cortadores de cana durante o período de 2008 a 2013, além de contar com pesquisa de campo realizada em Tavares, $\mathrm{PB}$, município de origem de um dos grupos de trabalhadores entrevistados.

Palavras-chave: cortadores de cana; migração; assalariamento temporário; estratégias empresariais; pagamento por produção.

\footnotetext{
${ }^{1}$ Mestre em Sociologia pela Universidade Estadual de Campinas (Unicamp) e doutoranda pelo Programa de Pós-Graduação em Sociologia da Universidade Estadual de Campinas (Unicamp); bolsista da Fundação de Amparo à Pesquisa do Estado de São Paulo (FAPESP); pesquisadora do Centro de Estudos Rurais (CERES) da Unicamp, Campinas, SP, Brasil, e-mail: jupitt16@yahoo.com.br.
} 
ABSTRACT: The purpose of this article is to analyze some general aspects of the conditions of life and work of Brazilian sugar cane cutters. To this end, the work was divided into two parts. The first will discuss who they are, from where and what are the reasons that lead these workers to seek employment in various sugar cane mills in the country. This first part is necessary for make clear the importance of temporary wage and income obtained through the same for rural workers and their families. In the second part, some of working conditions for sugar cane cutters will be presented, and, therefore, will analyze some of the main strategies employed by representatives of the sugar cane sector. The paper builds on research performed by the Usina Ester and Usina Costa Pinto (located in Cosmópolis and Piracicaba, São Paulo, respectively) and their sugar cane cutters during the period 2008 and 2013, and also rely on research field held in Tavares-PB, county of origin of a group of workers interviewed.

Keywords: sugar cane cutters; migration; temporary work; business strategies; wages for production.

\section{INTRODUÇÃO}

O objetivo do presente artigo é analisar alguns aspectos gerais das condições de vida e de trabalho dos cortadores de cana brasileiros. Para tanto, o trabalho em questão foi dividido em duas partes. Na primeira, será discutido quem são, de onde partem e quais os motivos que levam esses trabalhadores a buscarem emprego nas diversas usinas de açúcar e álcool do país. Essa primeira parte é necessária para que se possa compreender a importância desse assalariamento temporário e da renda obtida por seu intermédio para os trabalhadores rurais e suas famílias. Já na segunda parte, serão apresentadas as condições de trabalho dos cortadores de cana e, para tanto, serão analisadas algumas das principais estratégias de controle e de envolvimento empregadas pelos representantes do setor sucroalcooleiro. Nessa mesma seção, analisar-se-ão, de forma mais detalhada o pagamento por produção, forma de remuneração predominante 
dos cortadores de cana, buscando deixar claro não somente toda sua funcionalidade e importância para o setor em questão, como também as consequências nefastas que acarreta aos assalariados rurais.

Antes de dar início, é necessário dizer que toda a análise que se segue toma como base duas pesquisas: a realizada entre 2008 e 2010 junto à Usina Açucareira Ester S.A. (localizada em Cosmópolis, SP) ${ }^{2}$ e seus cortadores de cana e a realizada entre 2011 e 2013 junto à Usina Costa Pinto (localizada em Piracicaba, SP) ${ }^{3}$ e seus cortadores de cana. Como será mais bem explicado a seguir, além dos "lugares de destino" dos cortadores de cana, a pesquisa de campo também foi realizada em Tavares (município que faz parte do sertão paraibano), local de origem de um dos grupos de trabalhadores entrevistados.

No que se refere aos depoimentos dados pelos cortadores de cana, vale mencionar que, em função do compromisso de que nenhuma informação passível de identificar os sujeitos fosse divulgada, os nomes dos participantes referidos neste artigo foram alterados e substituídos por nomes fictícios, assim como os de todas as pessoas às quais eles se referiram nas entrevistas.

\section{MIGRAÇÃO E ASSALARIAMENTO TEMPORÁRIO NAS USINAS DE AÇÚCAR E ÁLCOOL}

Quem são os trabalhadores que buscam emprego nas diversas usinas de açúcar e álcool do país? De onde partem? Para onde vão? Quais os motivos que os levam a procurar esse tipo de serviço?

De forma geral, os cortadores de cana são trabalhadores de origem rural - principalmente do Nordeste e do norte de Minas Gerais - que deixam seus locais de origem em busca de trabalho assalariado nas usinas de açúcar e álcool localizadas, principalmente, no interior

\footnotetext{
${ }^{2}$ Essa primeira pesquisa deu origem à minha dissertação de mestrado, intitulada No eito da cana, a quadra é fechada: estratégias de dominação e resistência entre patrões e cortadores de cana em Cosmópolis-SP. 2010. Dissertação (Mestrado em Sociologia). Programa de Pós-graduação em Sociologia, Universidade Estadual de Campinas, Campinas, 232 fls. A referida pesquisa contou com financiamento da FAPESP, entre os anos de 2008 e 2010.

${ }^{3}$ Já essa segunda pesquisa é parte da tese de doutorado ainda em desenvolvimento, também financiada pela FAPESP e com previsão de término para o segundo semestre de 2014.
} 
do estado de São Paulo ${ }^{4}$. Na grande maioria dos casos, esses trabalhadores são do sexo masculino e jovens e acabam por se deslocar quase todos os anos a partir do mês de março (ou abril, dependendo da data do início da safra) para as cidades em que irão trabalhar. Como será explicado a seguir, os trabalhadores migrantes permanecem, em média, de oito a dez meses nestas localidades, residindo nos alojamentos coletivos das usinas, nas pensões das "cidades-dormitórios" ou em casas alugadas, retornando para suas regiões de origem somente no final de novembro ou dezembro, após o término da safra.

Encontrando-se destituídos de meios reais de sobrevivência em sua terra natal e, muitas vezes, sem outro tipo de alternativa - já que, na maioria dos casos, os municípios de origem dos trabalhadores rurais não oferecem muitas oportunidades de emprego -, estes acabam procurando trabalho nas diferentes usinas do país por ser essa uma atividade que lhes assegura algum tipo de renda e, consequentemente, a sobrevivência de si e de suas famílias.

No que se refere especificamente aos trabalhadores rurais naturais de Tavares $^{5}$ (município localizado no sertão paraibano), é preciso deixar claro que a maior parte deles - apesar de ser proprietária e residir em um pequeno lote de terra na zona rural do município - não consegue mais sobreviver somente da agricultura. A forte seca que assola a região há quase um século acabou inviabilizando ainda mais esse tipo de atividade, que foi se tornando cada vez mais residual. Como consequência desse processo, todos os gêneros alimentares necessários à sobrevivência das famílias (inclusive aqueles que antes eram produzidos pelos trabalhadores rurais paraibanos, tais como o milho e o feijão) passaram a ter de ser comprados nas feiras e nos mercados locais.

Assim, encontrando-se privados de seu meio de subsistência por excelência - uma vez que não conseguem mais tirar seu sustento de sua própria terra, fato que acaba tornando extremamente difícil

\footnotetext{
${ }^{4}$ Deve-se assinalar que, com a expansão dessas usinas ocorrida a partir dos anos 2000, as mesmas passaram a se alocar em outras regiões, que não aquelas tradicionalmente utilizadas, como Mato Grosso, Mato Grosso do Sul, Rio de Janeiro, Goiás e Minas Gerais, fato que acabou por alterar a cartografia dos movimentos migratórios.

${ }^{5}$ Tavares é o município de origem de muitos trabalhadores da Usina Costa Pinto. Possui aproximadamente 13 mil habitantes e faz parte do sertão da Paraíba.
} 
conseguir sobreviver somente da agricultura - gradativamente os trabalhadores rurais viram-se obrigados a buscar algum tipo de trabalho assalariado como meio de sobrevivência. Como mencionado, pelas próprias condições de sua região de origem - extremamente pobre e desindustrializada - raramente os trabalhadores conseguem algum tipo de emprego assalariado, fato que os leva a se deslocarem para outras regiões visando esse propósito.

Assim, diante da necessidade de viver da venda de sua força de trabalho, os trabalhadores rurais buscam o "mundo do emprego", que não está em seu universo local, mas em outra região. A alternativa para tais pessoas é migrar, é ir para o Sul (Garcia Jr., 1989). Nesse contexto, o assalariamento temporário nos centros urbanos ou nas usinas de açúcar e álcool passou a ser considerado uma estratégia de reprodução por parte dos próprios trabalhadores da unidade doméstica, uma vez que o dinheiro obtido por intermédio do trabalho remunerado no sul, além de compor e reequilibrar o escasso orçamento familiar, assegura a manutenção daqueles que não migraram.

Isso faz sentido ao lembrar que, em geral, não é a família inteira que migra, mas somente parte dela. Normalmente, são os homens que se deslocam, ficando as mulheres, as crianças e os idosos nas regiões de origem. A opção pela migração de poucos membros do grupo familiar dá-se pelas dificuldades e pelos custos de transporte, moradia e manutenção nas regiões de destino, que implicam altíssimos gastos para os trabalhadores. O mais comum é que o marido migre primeiro, deixando a família com os demais parentes. Em alguns casos, só depois de obter uma colocação relativamente estável e minimamente rendosa, é que aquele que migrou tem a oportunidade de ir buscar o restante da família para residir consigo (Durham, 1984; 2004; Garcia Jr., 1989).

Como será visto a seguir, no caso específico dos cortadores de cana, a migração da família inteira é ainda mais difícil de ocorrer. Isso porque aqueles homens que vão trabalhar como cortadores de cana e que levam suas esposas para residir consigo durante o período da safra são obrigados a alugar casas nas cidades de destino, já que são impossibilitados de residir nos alojamentos cedidos pelas usinas 
pelo fato de estarem acompanhados. Tal fato faz com que seja ainda mais caro se manter nas cidades de destino, uma vez que não somente o aluguel, mas todos os custos passam a ser multiplicados pelo número de familiares que residem juntos.

Essa situação faz com que a grande maioria dos homens que irá trabalhar como cortador de cana nas usinas seja obrigado a viajar sozinho, isto é, sem a companhia de sua família. Esta permanecerá em sua região de origem ao logo dos meses que compõem a safra da cana de açúcar e será responsável por todas as tarefas, sejam elas domésticas ou relativas à produção agrícola. Esse fato pôde ser confirmado ao longo da pesquisa de campo realizada no município de Tavares. Dos 43 entrevistados, somente dois trabalhadores afirmaram que, em algum momento, já tinham levado suas esposas para residir consigo nas cidades em que foram trabalhar. Todos os demais tinham migrado sozinhos, ficando o restante de seus grupos domésticos nos sitios em que residiam.

Entretanto, quer que se trate da movimentação de indivíduos ou de famílias, a direção do deslocamento depende, em grande medida, da tradição migratória do grupo de relações primárias original (Durham, 1984 e 2004; Menezes, 2002). Em geral, as pessoas migram para as localidades em que têm conterrâneos, amigos ou parentes ou para locais que lhes foram indicados por outros. De acordo com Durham (1984), mesmo as migrações que implicam mudanças radicais de estilos de vida “... são efetuadas dentro de um universo de referência organizado nos moldes da comunidade rural. Vai-se para onde está a família do irmão do pai, os antigos vizinhos, os amigos de infância" (Durham, 1984, p. 135).

E a migração para o trabalho no corte da cana não é diferente. Em muitos casos, aqueles que já atuaram como cortadores de cana indicam aos amigos as usinas em que trabalharam, os locais de saída dos ônibus e os turmeiros (funcionários das usinas responsáveis por selecionar e levar os trabalhadores para trabalharem nas mesmas). Formam-se, então, redes de informações e de solidariedade entre os migrantes, redes essas que permitem não só a comunicação e a troca de informações entre eles, mas também o auxílio mútuo (Menezes, 2002; Nogueira, 2010). 
Ressalta-se que, além de significar uma remuneração regular que não depende das variações climáticas (que prejudicam o ciclo agrícola) e de compor o escasso orçamento do grupo doméstico, para os trabalhadores rurais, o emprego no sul representa, ainda, uma renda monetária superior aos rendimentos obtidos na agricultura do norte e, por isso, é muito valorizado (Garcia Jr., 1989). Como já demonstrado (Guanais, 2010), na maioria dos casos, o dinheiro da cana - renda advinda do assalariamento temporário nas usinas de cana de açúcar - é um montante impossível de ser ganho nos locais de origem dos trabalhadores, de tal modo que a diferença de ganho que proporciona em comparação ao dinheiro conseguido por alguma atividade na terra natal é um dos fatores mais utilizados pelos próprios trabalhadores rurais para justificar sua migração.

Assim, o dinheiro da cana é extremamente valorizado pelos trabalhadores, não só porque assegura a sobrevivência de suas famílias, mas também porque proporciona um padrão de consumo diferenciado do que tinham antes de migrar. É por conta disso que é possível afirmar que o dinheiro da cana está relacionado ao aumento do consumo e à melhoria das condições materiais de vida dos trabalhadores rurais migrantes e de suas famílias. Essa conclusão só foi possível porque a pesquisa de campo foi dividida em duas partes, sendo realizada tanto nas cidades de destino dos cortadores de cana das Usinas Ester e Costa Pinto quanto no município de origem (Tavares, $\mathrm{PB}$ ) de um dos grupos de trabalhadores entrevistados ${ }^{6}$.

De forma geral, os resultados obtidos demonstraram que, em um primeiro momento - isto é, quando ainda estão trabalhando fora, longe de sua terra natal -, a maior parte dos cortadores de cana envia mensalmente uma quantia em dinheiro para a família que não migrou. Como visto, esse repasse financeiro é de extrema importância para assegurar a manutenção do grupo doméstico que

\footnotetext{
${ }^{6}$ A pesquisa de campo foi dividida em duas partes porque se partiu do pressuposto de que a realidade empírica de ambas as regiões - origem e destino - seria diferente, porém complementar, de modo que não seria possível compreender e analisar de forma satisfatória um dos polos sem ter em mente o outro. Somente conhecendo as localidades de origem dos trabalhadores rurais - sua história, as condições de vida e de trabalho de seus moradores etc. - é que se pode compreender a origem de muitos fatores presentes nos locais de destino dos cortadores de cana.
} 
permaneceu no norte, o qual, na maioria dos casos, conta somente com os parcos recursos advindos dos programas federais de transferência de renda, tais como o Bolsa Família, o Bolsa Escola, o Bolsa Estiagem e o Seguro Safra. Desse modo, é por intermédio da quantia enviada por aqueles que migraram que as famílias podem adquirir os insumos necessários à sua sobrevivência.

Interessante destacar aqui que essa quantia de dinheiro enviada à família que ficou na região de origem varia de trabalhador para trabalhador. Alguns cortadores de cana entrevistados relataram que conseguem enviar quase tudo o que recebem no mês. Outros enviam somente a quantia que sobra após pagarem todas as suas despesas. Outros, por sua vez, só enviam dinheiro quando conseguem. A partir da análise das entrevistas, foi possível perceber, ainda, que esse envio de dinheiro à família é mais fácil de ocorrer no caso dos cortadores de cana que residem nos alojamentos das usinas, já que, nesses casos, seus gastos mensais acabam sendo inferiores ${ }^{7}$ aos daqueles trabalhadores que não residem nesses alojamentos.

Entretanto, os próprios trabalhadores entrevistados fazem questão de ressaltar que enviar algum dinheiro à família - apesar de ser um dos maiores motivos (se não o maior) que os leva a deixar suas regiões de origem em busca de trabalho assalariado - não é possível sem certo tipo de esforço por parte deles. Em outras palavras: para que isso ocorra, é necessário que os cortadores de cana se privem não só daquilo que é considerado supérfluo, mas também de possíveis luxos nos meses em que estão "trabalhando fora". De acordo com eles, ao darem-se ao luxo de gastar parte do salário que recebem com gastos desnecessários, torna-se impossível economizar algum dinheiro.

Os resultados desta pesquisa demonstram, também, que, pos-

\footnotetext{
${ }^{7}$ De acordo com os trabalhadores, quando residem nos alojamentos das usinas, eles têm de arcar somente com o pagamento das refeições (valor esse que é diretamente e mensalmente descontado em sua folha de pagamento). Isso não ocorre quando os cortadores de cana residem em casas alugadas nas cidades em que trabalham, já que, nessas ocasiões, têm de custear todos os gastos (aluguel, água, luz, feira, alimentação etc.). É importante destacar que a diferença entre o salário que irão ganhar e os gastos que terão no mês é um dos fatores que influencia a escolha dos trabalhadores pelas usinas nas quais irão trabalhar. Assim, para aqueles que desejam guardar ou enviar uma quantia de dinheiro superior para a família, acaba sendo mais vantajoso optar pelas usinas que concedem alojamentos a seus trabalhadores.
} 
teriormente - ou seja, no período em que os cortadores de cana retornam para seus locais de origem -, a grande maioria investe a quantia que conseguiu poupar ao longo da safra, em sua própria terra natal, na compra de bens materiais para si e suas famílias. Assim, casas, terrenos, animais de criação, motos e eletrodomésticos, que muitas vezes não podiam ser comprados devido à falta de recursos dos trabalhadores rurais, passam a ser adquiridos por intermédio do dinheiro da cana. Verificou-se, além disso, que, quando possível, alguns trabalhadores conseguem ainda guardar alguma quantia (para fins de segurança futura) após terem adquirido tudo aquilo que era necessário.

Também foi possível perceber uma diferença no padrão de consumo dos cortadores de cana, que pode ser explicada a partir da perspectiva geracional. Verificou-se que os mais jovens, quando ainda são solteiros, ao retornarem de suas primeiras safras, acabam investindo grande parte da quantia que guardaram na compra de uma moto. Além desse gasto maior, esses mesmos jovens, quando voltam a seus locais de origem, também utilizam seu dinheiro para ter acesso a algum tipo de lazer, como festas, churrascos, viagens às cidades próximas etc.

De acordo com os próprios jovens entrevistados, esse tipo de gasto só é possível porque eles ainda não são casados e porque ainda residem na casa dos pais. Desse modo, pelo fato de ainda não serem os provedores de seu próprio núcleo familiar, os jovens estão autorizados a gastar parcela significativa do que ganharam nas usinas com eles próprios, situação que se alterará a partir do momento em que eles se casarem e constituírem família.

Essa situação não se aplica aos trabalhadores que já são casados e àqueles que têm a idade um pouco mais avançada. De acordo com a maioria dos entrevistados, o casamento e o nascimento dos filhos faz com que as responsabilidades que recaem sobre o "provedor" da família aumentem ainda mais. Isso ocorre porque, quando se tem esposa e filhos, o dinheiro recebido nas usinas precisa ser suficiente para alimentar, vestir, educar e dar saúde para todos aqueles que compõem o grupo doméstico (não sendo, assim, destinado somente ao custeio dos gastos daquele que recebe o salário). Vale destacar, também, que, no caso específico dos trabalhadores rurais 
de Tavares, a maioria de suas esposas não possui emprego ou fonte de renda sem ser aquela advinda dos programas federais de transferência de renda, o que acaba deixando as mulheres em uma situação de dependência ainda maior em relação aos esposos e ao dinheiro advindo do assalariamento temporário ${ }^{8}$.

Ainda de acordo com os trabalhadores entrevistados, por sua própria condição, "Os casados têm que ser mais ajuizados, têm que ter cabeça boa, cabeça no lugar" (José). Como demonstraram os resultados desta pesquisa, esses acabam investindo a maior parte do que conseguiram juntar ao longo da safra, em sua própria região de origem, na compra (ou reforma) de casas, de terrenos e de animais de criação. Mas, como fazem questão de ressaltar os próprios trabalhadores, para conseguirem isso, é preciso gastar o mínimo possível nas cidades em que trabalham como cortadores de cana.

Para esses trabalhadores, o dinheiro da cana não pode ser gasto à toa ou com qualquer coisa, já que foi a partir dele que conseguiram mudar de vida e adquirir tudo que possuem. A fala de Valmir serve bem para ilustrar essa situação. Quando interrogado sobre como havia conseguido ampliar sua casa e adquirir certos bens, o trabalhador respondeu: "Tudo o que tenho foi a cana que me deu".

Para que toda a argumentação acima possa ficar mais clara, a seguir serão citados dois excertos extraídos das entrevistas realizadas com os moradores de Tavares que trabalham como cortadores de cana na Usina Costa Pinto.

Pesquisador (P): Você consegue ficar aqui em Tavares se não for trabalhar no corte da cana?

J: Não, não consigo.

P: E o que você acha do seu salário?

J: Olha, bastante não dá não para ganhar, mas dá para o cara se

\footnotetext{
${ }^{8}$ Foi muito raro encontrar mulheres que residissem nos sitios (localizados nas zonas rurais de Tavares) e que tivessem algum tipo de emprego. Isso é um pouco mais fácil de acontecer com aquelas mulheres que deixaram sua residência na zona rural e que já moram de forma definitiva na parte "urbana" de Tavares. Em geral, estas são professoras da rede municipal de ensino, comerciárias das pequenas lojas ou dos armazéns da cidade e vendedoras "autônomas" de bijuterias e produtos de beleza (tais como Natura e Avon).
} 
manter com o que ganha. Tem que agradecer a Deus pelo pouco.

P: E o que você faz com o que ganha nas usinas?

J: O cara guarda, investe em alguma coisa: compra um pedaço de terra, uma casa...

\section{P: Aqui [em Tavares]?}

$J:$ É, aqui, no nosso município.

P: E a maioria compra o quê quando volta?

J: Uns compram terreno, outros casa, outros compram moto.

P: E lá nas cidades em que vocês trabalham, vocês gastam bastante?

J: Lá não, lá é só o básico, só o básico. Porque sair lá gasta... o cara vai atrás de trazer e se o cara for cair na farra lá aí não trás. Porque lá o custo de vida não é igual daqui. Lá o custo de vida é muito caro. E aqui não, tudo tem um pedaço de terra, uma casa, e não é igual. Eu mesmo não saio de jeito nenhum. Só saio para tirar o dinheiro na cidade porque é obrigado.

P: E o que você ganha nas usinas você consegue guardar um pouco, enviar para a família que ficou em Tavares e ainda viver na cidade em que trabalha?

$J: E$ E, lá [na cidade de destino] a gente coloca num banco. Essas casas do pessoal daqui [de Tavares] já são de lá, é tudo construído com o dinheiro de lá.

$P$ : E as coisas que vocês compram, vocês compram na cidade em que vocês trabalham ou vocês deixam para comprar aqui?

$J$ : A gente compra aqui [em Tavares]. Lá eu não invisto nada, não. O investimento é todo aqui, em gado, numa coisinha, é tudo aqui (Josias).

P: O que vocês compram com o dinheiro que vocês recebem nas usinas?

A: Ah, a gente investe aqui [em Tavares], compra terreno, outros compram gado - quem tem muita terra pra criar. Compra carro... tem uns deles bem de vida aqui do corte de cana, viu. Eu não vou mentir pra você: eu dou graças a Deus pela coragem que Deus me deu, é o serviço pior que existe, mas eu levanto a mão pro céu e 
agradeço o que tenho hoje, agradeço, é da cana hoje.

P: Tudo o que você tem veio da cana?

A: É da cana, tudo, tudo. O que eu consegui aqui da roça quando eu tava com dezoito anos de idade - eu vou falar pra você porque eu não tenho vergonha - até um calçado pra eu calçar eu não consegui comprar aqui, não, nesse periodo todinho que eu vivi aqui. E depois que eu viajei, que eu completei a idade e viajei, graças a Deus as coisas só foi subindo. Graças a Deus tô feliz hoje.

$P$ : Então você investiu seu dinheiro?

A: É, investi aqui [em Tavares], tenho um terreno ali que eu vou construir na semana que vem, tudo com o dinheiro da cana. Tenho uma motinho - dinheiro da cana - e eu pretendo, se Deus quiser, daqui uns dois anos comprar uma D-20 pra dar uma voltinha com a mulher e os meninos [risos]. O pessoal daqui de primeiro sofria muito, mas hoje esse pessoal que sofria, se você vê hoje você não acredita. Lá no sítio que eu morava-meu pai ainda mora lá-tinha deles que não tinha nem um chinelo pra calçar... e hoje eles têm seus trinta, quarenta mil real no banco, têm sua moto zero pra andar, se você ver é coisa pra não acreditar.

$P:$ E eles cortaram cana?

A: É tudo do corte da cana, do corte da cana. Eu tenho uns primos ali, se você ver o prediozinho que eles fizeram lá, eles têm D-20 e dinheiro bastante na conta, viu (André).

Como foi possível perceber, a reforma da casa, a compra de um pedaço de terra e a aquisição de bens de consumo, por exemplo, deixam de ser tão inacessíveis e passam a fazer parte dos planos de muitos cortadores de cana. Em sua análise, Garcia Jr. (1989) já havia atentado para o fato de que o assalariamento no sul é visto pelos próprios trabalhadores como "... uma estratégia de grande destaque quando se trata de acumular recursos monetários necessários à compra e/ou construção de casa, sítio ou dinheiro para o negócio [...] é mesmo considerada estratégia prioritária" (Garcia Jr., 1989, p. 152).

Para finalizar esta primeira parte, é preciso destacar que, na maioria das vezes, o dinheiro da cana é a única fonte de renda que 
os trabalhadores rurais e suas famílias possuem. Por isso, o salário recebido ao longo da safra (oito ou dez meses) tem de conseguir assegurar a sobrevivência dos cortadores de cana em suas regiões de destino e a de sua família nas comunidades de origem, além de, na maioria das vezes, ter de durar no período da entressafra. Não se pode esquecer que, em geral, os cortadores de cana regressam no final do ano para sua terra natal e por lá permanecem alguns poucos meses até a safra agrícola da cana reiniciar novamente. Durante esse intervalo, que varia de dois a quatro meses, muito raramente os trabalhadores rurais contam com algum tipo de renda, e, por isso, é muito importante que possam contar com uma quantia (por menor que seja) de dinheiro que tenha sido guardado ao longo do tempo em que trabalharam fora. Esse pecúlio possibilitará aos trabalhadores fazerem seus roçados, comprarem os insumos agrícolas necessários (sementes e outros), renovarem suas plantações, alimentarem-se etc.

Até aqui foram apresentados quem são, de onde partem, para onde vão e os motivos que levam os trabalhadores a buscarem emprego nas mais variadas usinas de açúcar e álcool do país. Nesta mesma seção, também se buscou deixar claro a importância desse assalariamento temporário e da renda obtida por seu intermédio para os trabalhadores rurais e suas famílias. Na seção seguinte, serão analisadas as condições de trabalho desses mesmos homens nas usinas em que vão trabalhar como cortadores de cana, demonstrando as dificuldades enfrentadas por eles para se manterem em seu emprego e para conseguirem juntar algum pecúlio. Para tanto, serão discutidas algumas das principais estratégias de controle e de envolvimento empregadas pelos representantes do setor sucroalcooleiro. Como já mencionado na introdução, por se tratar de uma das mais importantes estratégias utilizadas pelas usinas, nessa mesma parte também será explorado de forma mais detida o pagamento por produção, forma de remuneração predominante dos cortadores de cana, buscando deixar claro não só toda sua funcionalidade e importância para o setor em questão, mas também as consequências nefastas que acarreta aos assalariados rurais. 


\section{O LABOR NOS CANAVIAIS: CONDIÇÕES DE TRABA- LHO E ESTRATÉGIAS EMPRESARIAIS}

Após viajarem durante dias de ônibus, os trabalhadores chegam às cidades em que vão atuar como cortadores de cana. Os que vêm pela primeira vez ficam assustados com as altas exigências do trabalho, com os altos níveis de produtividade a serem atingidos e com as péssimas condições de trabalho. O ritmo frenético da produção, as várias formas de exploração a que estão submetidos, as enormes e variadas cobranças sobre a qualidade do serviço a ser executado, os baixos salários, as condições precárias de moradia e de alimentação, o tratamento ríspido que recebem de seus superiores e a imposição de metas diárias de produtividade compõem o cenário encontrado pelos trabalhadores rurais e farão parte de seu cotidiano durante todos os meses da safra.

Em função dos limites do presente artigo, não poderão ser abordados todos os aspectos das condições de trabalho enfrentadas pelos cortadores de cana, como os roubos no momento da pesagem da cana cortada, a má qualidade da alimentação recebida e as péssimas condições dos alojamentos cedidos pelas usinas. Entretanto, por intermédio da apresentação de algumas das principais estratégias utilizadas pelos representantes do setor sucroalcooleiro, serão analisadas determinadas condições de trabalho dos cortadores de cana.

Para que seja possível explorar de maneira mais satisfatória essas diferentes estratégias, estas serão divididas em três blocos e analisadas separadamente. Primeiramente, serão analisadas as estratégias que são elaboradas e utilizadas pelas usinas como formas de controle dos cortadores de cana e de seu trabalho. Em um segundo momento, serão analisadas aquelas estratégias que objetivam o envolvimento dos assalariados rurais com o trabalho que desempenham e com o ideário da usina para a qual trabalham. Por último, será analisado o pagamento por produção, uma estratégia empresarial que permite, ao mesmo tempo, o controle e o envolvimento dos cortadores de cana. 
1) Estratégias de controle:

a) Média

Uma das mais importantes estratégias utilizadas pelas usinas é a imposição de uma média, isto é, de uma produtividade diária mínima medida em toneladas, a ser atingida por todos os cortadores de cana. Estes são obrigados a atingir tal média - que, atualmente, gira em torno de dez ou doze toneladas/dia de cana por trabalhador - para não serem demitidos a qualquer momento. Como será mais bem explicado a seguir, essa imposição da média está intimamente vinculada ao pagamento por produção, forma de remuneração predominante dos cortadores de cana, e pode ser vista tanto como uma violência dirigida contra os canavieiros quanto como uma forma de domínio e de controle do trabalho dos cortadores de cana.

Não é difícil perceber, também, que essa imposição da média diária de produção é extremamente importante e interessante para as usinas, que a utilizam como uma forma de selecionar somente os "melhores trabalhadores", isto é, os mais produtivos - os que realmente as interessam. Já aqueles que não conseguem atingir a média diária imposta acabam sendo dispensados independentemente do período da safra.

Além desse primeiro aspecto, não se pode deixar de ressaltar aqui que, com o passar do tempo, a média diária a ser atingida pelos cortadores de cana aumentou significativamente. De acordo com a pesquisadora Maria Aparecida de Moraes Silva, na década de 1980, a média exigida era de cinco a oito toneladas de cana cortada por dia; em 1990, passa para nove toneladas; em 2000, passa para dez; e em 2004, passa para uma quantia que pode variar de doze até quinze toneladas por dia (Silva, 2006). Com isso, é possível perceber, também, que a imposição de uma média diária cada vez maior acaba funcionando como o definidor do aumento da produtividade do trabalho dos cortadores de cana, que, como já mencionado, são obrigados a atingir a meta estipulada para conseguirem assegurar seus postos de trabalho. Nesse contexto caracterizado por pressões e cobranças por parte das usinas e por demissões daqueles que não conseguem atingir a média, a rotatividade dos cortadores de cana torna-se muito alta.

Não se pode esquecer, ainda, que a elevação continuada da 
média induz os assalariados rurais aos acidentes de trabalho, ao sofrimento, a doenças e até mesmo à morte. De acordo com Silva (2005), a imposição de uma média diária e sua aceitação por parte dos trabalhadores constitui um dos elos das chamadas "correntes invisíveis" que atam os cortadores de cana às estratégias de dominação das usinas, podendo ser vista também como uma espécie de coerção moral, consistindo em uma das formas possíveis da atual intensificação da exploração do trabalho pelo agronegócio.

Consoante a essa perspectiva está a opinião de José Roberto Pereira Novaes. De acordo com o autor, com a introdução de novos arranjos produtivos, as usinas de açúcar e álcool passaram a exigir maior produtividade e mais disciplina no trabalho. Ao mesmo tempo, provocaram uma segmentação maior da força de trabalho, intensificaram a precarização e imprimiram uma nova dinâmica na seleção de seus trabalhadores. Ainda para Novaes (2007b), esse aumento da produtividade dos cortadores de cana ocorreu não somente por intermédio da imposição da média diária, mas também por meio dos programas de treinamento implantados nas usinas, os quais, como será visto a seguir, visam não somente à melhoria do corte manual da cana, mas principalmente à adequação dos cortadores de cana ao ideário da usina para a qual trabalham.

\section{b) As listas negras e os ganchos}

Tais estratégias são bastante antigas e amplamente utilizadas pelas usinas em geral como formas de sujeição e controle social dos cortadores de cana. Normalmente, cada usina elabora uma lista na qual consta o nome daqueles trabalhadores que trabalharam (ou que ainda trabalham) para ela, mas que estão "marcados" por terem desobedecido às normas impostas ou por qualquer outro motivo. A organização ou o envolvimento dos cortadores de cana em greves e a participação ativa em um sindicato constituem critérios que, muitas vezes, são suficientes para incluir os nomes dos envolvidos em uma lista negra. Essas listas circulam entre as várias usinas do país, o que permite que estas tomem conhecimento de todos os trabalhadores que estão citados em tais listas, podendo, portanto, não vir a contratá-los. 
De acordo com Maria Aparecida de Moraes Silva (1999), as listas negras são utilizadas amplamente pela maioria das usinas do país, já que servem como o antídoto mais eficaz para a correção de condutas e comportamentos dos trabalhadores. É importante mencionar que tais listas são produzidas nos escritórios das usinas mediante a centralização do controle e distribuídas aos empreiteiros para que não venham a contratar aqueles trabalhadores que constam nas listas. Dessa forma, pelo controle do registro, aqueles "marcados" são impedidos de trabalhar por um tempo determinado, o qual pode variar bastante, chegando a atingir até três anos.

Já os ganchos são os mecanismos criados e utilizados para suspender por um tempo aquele cortador de cana que não tenha executado bem sua tarefa ou que tenha desobedecido ao fiscal. Tal suspensão é aplicada pelo fiscal responsável por aquele trabalhador, ficando a seu critério decidir qual a duração da punição. Não é difícil perceber que os ganchos representam uma redução no salário mensal dos cortadores de cana, já que, ao serem suspensos, estes são impedidos de trabalhar por um tempo determinado, deixando, portanto, de receber pelos dias em que não cortaram cana.

Além disso, os ganchos funcionam como um mecanismo de pressão, ou seja, como uma forma utilizada pelos fiscais de turma para controlar e disciplinar ainda mais os cortadores de cana, fazendo com que estes cumpram de maneira exemplar todas as tarefas que compõem o seu trabalho.

c) Os fiscais de turma

Os fiscais de turma constituem uma das categorias de funcionários mais importantes para as usinas, já que são os responsáveis pelo acompanhamento e pela fiscalização dos cortadores de cana quando estes estão no interior dos canaviais. São os fiscais que distribuem e supervisionam o trabalho da turma, verificando não somente se os cortadores de cana estão realizando a contento todas as atividades prescritas, mas também todos os comportamentos e as atitudes dos trabalhadores durante o tempo em que estão trabalhando. Ao fazerem isso, garantem a disciplina de todos os cortadores de 
cana, atitude essa imprescindível para as usinas.

A figura dos fiscais de turma é bastante antiga e já foi amplamente analisada por vários pesquisadores. Em Errantes do fim do século (1999), Maria Aparecida de Moraes Silva também analisa a figura do fiscal de turma, denominada por ela de "feitor". De acordo com a autora, o sucesso de uma usina não se deve à sua superioridade técnica, mas ao controle exercido sobre os trabalhadores. Nesse sentido, a disciplina e a fiscalização são utilizadas com vistas à diminuição de custos.

No contexto em que tempo e disciplina são considerados fatores essenciais para se auferir maiores ganhos, é possível entender a obrigação que recai sobre os trabalhadores rurais de estarem em contínuo movimento, não podendo ficar parados sem mexer o corpo. Para isso, os "mediadores da dominação" (Silva, 1999) exercem um olhar constante e minucioso sobre os cortadores de cana, olhar esse que deve ser capaz de controlar cada gesto, cada ritmo e cada conduta dos trabalhadores, buscando não deixar escapar uma mínima movimentação sequer.

2) Estratégias de envolvimento:

A partir de agora serão analisados outros tipos de estratégias empregadas pelos representantes do setor sucroalcooleiro. De início, é preciso ressaltar que tais estratégias são inúmeras e se diferenciam das anteriores, uma vez que têm como objetivo central obter envolvimento dos trabalhadores com a atividade que desempenham e com o ideário da empresa para a qual trabalham.

Assim, é importante ter em mente que o setor sucroalcooleiro brasileiro passou por profundas transformações a partir da década de 1990. Nesse sentido, a profissionalização da administração empresarial, a formalização da estrutura de cargos e salários e a redução dos postos de trabalho (decorrentes de um considerável processo de reengenharia) são fatores que se fazem presentes na grande maioria das usinas do país atualmente. De acordo com vários pesquisadores do tema, dentre eles Marcos Lázaro Prado (2008), nos dias de hoje, é possível perceber de forma mais significativa a inserção de novas posturas administrativas, formuladas segundo princípios da flexibilização, que buscam de maneira contundente a redução de conflitos 
entre capital e trabalho, lançando mão, para isso, do envolvimento dos trabalhadores com as metas organizacionais.

Ainda de acordo com Prado (2008), a realização de treinamentos destinados à execução das tarefas do cargo sempre foi fato comum nas empresas ligadas ao setor sucroalcooleiro, muito embora tenha sido intensificada nos últimos anos. O que se apresenta como inovação é o fato de que tais treinamentos passaram a assumir um caráter de "preparação ideológica". Com isso, observa-se que, desde o ingresso na organização, o funcionário é sujeitado a constantes treinamentos de caráter motivacional, em que se reitera uma suposta visão positiva - de importância e preocupação - da empresa para com seu corpo profissional.

Sob esse princípio, vincula-se todo um conjunto de pequenos projetos executados pelas usinas e que corroboram para essa suposta mudança de postura. Salas de leitura, ginástica laboral, projetos de alfabetização, distribuição de bebidas isotônicas no campo e competições desportivas são exemplos desses pequenos projetos que acabam contribuindo para consolidar essa nova imagem das usinas para seus trabalhadores. Não se pode deixar de perceber que tais procedimentos que associam a empresa à sua força de trabalho, convencendo-a, assim, da importância de seu envolvimento, acabam possibilitando a continuidade e até mesmo a ampliação de sua exploração.

Diante da enorme multiplicidade de estratégias voltadas para o envolvimento cada vez maior dos trabalhadores rurais com a atividade que desempenham e com a usina para a qual trabalham, optouse por descrever, neste artigo, somente aquelas que se fazem presentes nas usinas em que foram realizadas as pesquisas.

\footnotetext{
9 A distribuição de bebidas isotônicas (os também conhecidos como "sorinho" ou "suquinho") pelas usinas aos trabalhadores é uma questão muito polêmica. Dentre as causas para isso, está o desconhecimento das substâncias que compõem este repositor e dos possíveis danos que pode trazer ao organismo dos cortadores de cana. Alguns estudos começaram a ser feitos (em especial pelas vigilâncias sanitárias), e descobriu-se que a bebida não é um mero repositor energético como alegam as usinas, mas sim uma espécie de estimulante, fato que, por si só, merece ser investigado mais a fundo. Alguns pesquisadores acreditam que essa bebida energética é fornecida aos trabalhadores para estimulá-los a cortar mais cana, já que, ao ingeri-la, estes se sentem mais dispostos e energizados. Para mais informações sobre os repositores energéticos, ver Alves (2008).
} 


\section{a) Os treinamentos}

De maneira geral, tanto os fiscais de turma quanto os cortadores de cana da grande maioria das usinas do Brasil passam por treinamentos oferecidos pelas empresas para que trabalham. Em quase todos os casos, tais cursos têm um caráter compulsório, ou seja, todos são obrigados a fazer, e em geral são oferecidos por um grupo de funcionários ligados ao Departamento de Recursos Humanos das usinas.

No caso específico da Usina Ester, o treinamento voltado aos fiscais possui caráter motivacional e tem como objetivo ensinar a tais funcionários as formas mais apropriadas de tratar os cortadores de cana. É importante destacar, também, que nesse curso são dadas "dicas sobre liderança". Além disso, os cortadores de cana também são obrigados a fazer um curso oferecido pela Usina Ester, mas de natureza totalmente distinta do anterior. $\mathrm{O}$ treinamento destinado aos trabalhadores é anual e oferecido no início da safra.

Além de ensinar aos trabalhadores as melhores técnicas de cortar a cana com vistas ao seu melhor aproveitamento, o treinamento em questão tem o objetivo de difundir as normas da Usina Ester. Assim, os cortadores de cana são instruídos a respeitar a hierarquia existente na empresa e a se comportarem adequadamente, evitando, dessa forma, desavenças com seus superiores.

É importante destacar, ainda, que os treinamentos são peças fundamentais no processo de implantação dos programas de qualidade total e visam motivar e envolver todos na perseguição dos objetivos estratégicos da empresa: produtividade e qualidade. A reestruturação produtiva (seja ela das empresas urbanas ou das usinas de açúcar e álcool) acaba por exigir a redefinição dos objetivos e das metas, ou seja, da missão organizacional. O treinamento é, portanto, o modo privilegiado de difusão e homogeneização dos objetivos em todas as áreas da empresa.

Por fim, é importante mencionar que os treinamentos abordam as regras para que os cortadores de cana possam usufruir dos benefícios assistenciais, incluindo bom comportamento diante dos chefes e colegas de turma e, sobretudo, cumprimento das metas de produção. Nesses momentos, é também colocada a necessidade de os trabalhadores rurais 
observarem um conjunto de comportamentos de conteúdo moral - referentes à proibição de atitudes que podem gerar ócio ou violência - e político - relativos à participação nas organizações sindicais.

b) Os Programas de Participação nos Resultados (PPR)

Tais programas consistem em uma bonificação monetária extra que todos os funcionários da usina recebem - sejam eles gerentes ou trabalhadores rurais - caso a empresa cumpra plenamente suas metas de produção e obtenha lucro. Deve-se mencionar que os Programas de Participação nos Resultados fazem parte da política de muitas usinas atualmente, inclusive da Usina Ester.

É importante perceber que tais programas são utilizados pelas empresas em geral como uma forma de melhorar sua imagem perante todos os seus funcionários. A partir dos PPRs, as empresas podem dividir seus lucros com todos os seus "colaboradores", alegando que tal política é extremamente correta, pois nada mais justo do que dividir tudo o que foi conseguido entre todos aqueles que ajudaram a obter tal conquista. Entretanto, é preciso ver o que está implícito nessa importante política. Na realidade, tais programas acabam servindo como um estímulo para que todos os funcionários se envolvam com as metas da empresa para a qual trabalham - independentemente do cargo que ocupam -, buscando persegui-las (Krein, 1999).

A aplicação de tais programas também acaba por favorecer a busca pelo aumento de produtividade, intensificando a participação e o comprometimento dos trabalhadores que, mediante a realização de metas estabelecidas pela empresa, podem obter valores complementares às suas remunerações. A implantação dos PPRs na Usina Ester surtiu efeito no que se refere ao aumento de sua produtividade, já que, na safra de 2005/2006, a usina ganhou o "Prêmio empresa campeã de produtividade agrícola", concedido pelo Instituto de Desenvolvimento Agroindustrial (IDEA), sendo, por isso, classificada entre as doze melhores empresas canavieiras do Brasil.

Por fim, é preciso afirmar que, embora a negociação dos PPRs tenha sofrido impedimentos, principalmente de ordem legal, com a regulamentação da Lei n. ${ }^{\circ}$ 10.101, de dezembro de 2000, a qual es- 
tabeleceu que a participação nos lucros da empresa seria objeto de negociação entre a empresa e seus empregados, mediante a comissão escolhida pelas partes, integrada, também, por representantes sindicais; a implantação de tais programas tornou-se uma realidade e atingiu parte considerável do setor sucroalcooleiro brasileiro.

\section{c) Prêmio da semana}

Consiste em uma prática muito comum, sendo recorrentemente utilizada pelas usinas para instigar seus cortadores de cana a aumentar cada dia mais sua produtividade. Essa estratégia patronal consiste na premiação do trabalhador mais produtivo, o qual, por sua vez, vem a receber um brinde (que pode variar de um celular até uma moto) em função de ter superado os demais trabalhadores no quesito quantidade de cana cortada. $\mathrm{O}$ vencedor de tal competição fica conhecido como Podão de ouro. Não é difícil perceber que tal prática acaba por incitar ainda mais a competição entre os canavieiros, que, muitas vezes, passam a se empenhar além do suportável para cortar mais cana do que os demais com vistas a ganhar os prêmios oferecidos pelas usinas. Quando inseridos nesse contexto competitivo, também não são raras as ocasiões em que muitos cortadores de cana começam a ver os companheiros de trabalho como rivais e concorrentes que podem vir a superá-los, o que acaba prejudicando o relacionamento entre eles.

Esse tipo de premiação já chamou atenção de alguns pesquisadores, como Paixão (1994) e Thomaz Júnior (2002), os quais perceberam que consistia em uma prática amplamente difundida entre as usinas brasileiras, que a utilizavam não só como um verdadeiro estímulo para elevar a produtividade dos cortadores de cana, mas também como uma estratégia para tornar os trabalhadores rurais mais cooperativos e envolvidos com os objetivos da empresa para a qual trabalhavam.

Por último, é preciso mencionar que o Prêmio da semana é uma das mais antigas e importantes estratégias utilizadas pelas usinas, estando intimamente vinculado à forma de remuneração dos cortadores de cana, o pagamento por produção, como será visto a seguir. 
3) Estratégia de controle e de envolvimento:

a) O pagamento por produção

Antes de analisar o que é o pagamento por produção, é necessário deixar claro que, no presente artigo, essa estratégia receberá mais destaque do que as demais, justamente porque pode ser considerado tanto como uma estratégia de controle quanto de envolvimento dos trabalhadores rurais. Como se buscará explicar a seguir, tal modalidade salarial é utilizada pelo setor sucroalcooleiro não somente para controlar os cortadores de cana e os resultados de seu trabalho, mas também para envolvê-los com a atividade que desempenham e com as metas estabelecidas pela usina para a qual trabalham. Isso se deve, dentre outros fatores, à própria lógica do pagamento por produção, que, como veremos, possibilita que seja utilizado para ambos os propósitos. Ao longo da exposição, também será demonstrado toda a sua funcionalidade e importância para o setor em questão, bem como algumas das consequências nefastas que acarreta aos assalariados rurais.

Mas, afinal, o que é o pagamento por produção? Em que ele se diferencia das demais formas de pagamento? O pagamento por produção é uma forma específica de remuneração que está presente não só no mundo rural ${ }^{10}$ como também no urbano e tem ampla base legal, sendo previsto no artigo 457, $\S 1^{\circ}$ da Consolidação das Leis de Trabalho (CLT), bem como incontroversa aceitação doutrinária e jurisprudencial. De acordo com sua lógica, a remuneração de um trabalhador é equivalente à quantidade de mercadorias por ele produzida. Desse modo, o salário a ser recebido não terá como base as horas por ele trabalhadas, mas sim a quantidade de mercadorias que serão produzidas no decorrer de sua jornada de trabalho. No caso específico dos cortadores de cana, o ganho por produção pode ser resumido e explicado pela seguinte lógica: "quanto mais se corta, mais se ganha".

Evidente que a opção por remunerar os trabalhadores do corte da cana por meio do pagamento por produção não é aleatória (Adissi; Spagnul, 1989; Paixão, 1994; Alves, 2008). Como cada trabalhador

\footnotetext{
${ }^{10}$ Além do setor sucroalcooleiro, muitas outras culturas agrícolas fazem uso do pagamento por produção, tais como as lavouras de laranja, de café e de tomate.
} 
recebe um salário condizente com o que produz, a quantidade produzida por ele tem de ser auferida para que se possa saber quanto será sua remuneração. Mas, no caso específico dos cortadores de cana, não são eles próprios que calculam a quantidade de cana que cortaram em um dia de trabalho; são alguns funcionários das usinas, em geral os fiscais, que, no final do dia, medem com um compasso (de dois metros de extensão) a quantidade de metros que cada trabalhador cortou. Normalmente, tal medição é realizada quando os trabalhadores não estão mais nos canaviais, e, por isso, estes não podem acompanhá-la. Em função disso, muitas vezes os cortadores de cana reclamam da medição realizada pelo fiscal, pois avaliam que os funcionários da usina submensuraram a quantidade de cana cortada. Como recebem por produção, a diferença de metros faz muita diferença, pois irá interferir diretamente no salário a ser recebido.

É por isso que a utilização de tal forma de remuneração é extremamente importante para as usinas, já que, a um só tempo, impede que os cortadores de cana adquiram o controle de seu processo de trabalho e, consequentemente, de seu pagamento, bem como permite que as usinas tenham a noção exata da produtividade e da intensidade de trabalho de cada um de seus empregados.

Como cada trabalhador recebe pelo que produz, ao comparar os salários de todos os empregados, torna-se fácil para as empresas descobrirem quais são aqueles que cortam mais e menos cana. Isso permite que as usinas mantenham em seu quadro de funcionários somente aqueles cortadores de cana mais produtivos e demitam todos os que não conseguem atingir os índices de produtividade previamente estipulados. A questão fica mais clara se for levado em conta que a lógica empresarial do setor sucroalcooleiro não se restringe à utilização do pagamento por produção. Como já explicado, juntamente com tal forma de remuneração, passaram a ser utilizadas outras estratégias desenvolvidas pelos representantes desse setor, que permitem que as usinas obtenham um controle extremamente rígido dos cortadores de cana e dos resultados de sua produção. Um exemplo de tal estratégia é a imposição da média, analisada anteriormente.

Como já mencionado, o crescimento exorbitante da média 
teve de ser acompanhado pelo aumento da produtividade dos cortadores de cana, os quais passaram a ser obrigados a aumentar a intensidade de seu trabalho e a quantidade de cana cortada por dia para que pudessem permanecer na usina para a qual trabalhavam. Esse fato fez com que alguns pesquisadores, tais como Francisco Alves (2006 e 2008) e José Roberto Pereira Novaes (2007a), defendessem a ideia de que o pagamento por produção deve ser visto como uma das formas de controle do trabalho no corte da cana em um contexto de modernização e intensificação da produção. Isso porque tal forma específica de remuneração, ao mesmo tempo em que incentiva a intensificação do trabalho e a extensão da jornada de trabalho (Marx, 2013) - servindo, assim, como um acicate ao trabalho excessivo dos cortadores de cana -, funciona como um engenhoso método de interiorização da disciplina e do autocontrole do trabalhador.

Ao ter sua remuneração atrelada à quantidade de "peças" (de produtos, de mercadorias) que é capaz de produzir em determinado tempo, nada mais compreensível que os trabalhadores invistam o máximo possível de suas forças, de suas energias e de sua disposição para produzir cada vez mais, aumentando crescentemente sua produtividade. Mas, ao analisar melhor esse conjunto de ações, percebe-se que ele também acaba sendo extremamente interessante para os donos dos meios de produção, que veem a produtividade de seus trabalhadores aumentando sem que haja necessidade de fazer grandes investimentos em máquinas e equipamentos ou em melhorias das condições de trabalho. Em decorrência disso, sentem-se à vontade para impor um aumento na intensidade do trabalho sem serem obrigados a entrar em discórdia com os trabalhadores, os quais, como foi dito, também estão interessados na elevação de sua produtividade para que, assim, possam receber um aumento em seu salário (Marx, 2013).

Além disso, quando recebem por produção, os trabalhadores também têm outro interesse: o prolongamento de sua jornada de trabalho, para que, assim, possam trabalhar por mais tempo a fim de aumentar sua produção diária, já que, ao produzirem mais, recebem mais.

Esse maior investimento por parte dos cortadores de cana em seu trabalho estimulado pelo pagamento por produção pôde ser 
comprovado por intermédio da pesquisa de campo. Mesmo tendo asseguradas a pausa de uma hora para o almoço (que se dá entre 10 e 11 horas da manhã ou entre 11 e 12 horas) ${ }^{11}$ e as duas pausas de dez minutos para descanso (que devem ser feitas de manhã e de tarde), foi possível observar que muitos deles não obedeciam a esses momentos de descanso. Especialmente no que se refere ao almoço, muitos cortadores de cana optavam por almoçar em poucos minutos para poderem retornar o mais rápido possível para o trabalho.

Ao longo das entrevistas, grande parte dos trabalhadores relatou que, pelo fato de receberem por produção, muitos não fazem as pausas que lhe são garantidas, já que, ao pararem de cortar cana, diminuem sua produtividade e consequentemente, seu salário. Além de não terem interesse em suspender seu trabalho nem mesmo nos momentos previstos para seu próprio descanso, a maioria dos cortadores de cana declarou que, se pudesse, trabalharia mais dias ou mais horas na semana com vistas a obter um acréscimo ainda maior em sua remuneração. De acordo com esses trabalhadores, não adianta nada deixar sua terra natal e permanecer tanto tempo longe da família se o salário a ser recebido nas usinas não "for bom", isto é, se não compensar. "Se for para não trabalhar, ou se for pra ganhar pouco, é melhor ficar lá na terra da gente. Se o cabra vem pra cá ele tem que trabalhar, tem que vir atrás de levar algo, senão não adianta” (Antonio).

Outros aspectos também merecem ser destacados quando o assunto é o pagamento por produção. A partir do momento em que os trabalhadores são remunerados de acordo com a quantidade que produziram no decorrer de sua jornada de trabalho, o pagamento recebido por cada um pode diferir. Nesse sentido, as grandes diferenças de salário variam de acordo com critérios tais como força, habilidade, energia e persistência de cada trabalhador em particular. Assim, a utilização dessa forma de remuneração traz outra consequência: a individualização dos salários. Os salários dos trabalhadores rurais passam a ser individualizados, da mesma forma que sua produção.

Nesse contexto, não é difícil perceber que, por suas próprias

\footnotetext{
${ }^{11}$ Na parada para o almoço. as "frentes de trabalho" da Usina Costa Pinto são divididas em duas turmas. A primeira turma almoça das 10 às 11 horas, enquanto a outra turma continua trabalhando. Depois, entre 11 horas e meio-dia, a situação inverte-se, isto é, enquanto a segunda turma almoça, a primeira volta ao trabalho.
} 
características, o pagamento por produção acaba por reforçar as diferenças dos trabalhadores individualmente, provocando, assim, não só diferenciações entre seus rendimentos, mas também o estabelecimento da competição entre eles. Em outras palavras: se alguém quiser ganhar um pouco mais, terá de trabalhar mais que seus companheiros de trabalho e ser mais resistente do que os que estão à sua volta. Em um ambiente como esse, a competitividade e a rivalidade surgem quase como uma consequência natural, o que acaba prejudicando o relacionamento entre os próprios cortadores de cana.

Diante do que foi exposto, é possível entender o motivo pelo qual o pagamento por produção é uma das mais importantes estratégias utilizadas pelo setor sucroalcooleiro. Como se tentou demonstrar, tal forma específica de remuneração pode ser vista tanto como uma estratégia de controle quanto de envolvimento dos trabalhadores rurais. Ao mesmo tempo em que é utilizado como forma de controlar os cortadores de cana e evitar que obtenham o controle de seu processo de trabalho, por sua própria lógica, o pagamento por produção estimula o envolvimento dos cortadores de cana com a atividade que desempenham. Como visto, tal modalidade salarial incita os assalariados a trabalharem de forma mais intensa e/ou a prolongarem sua jornada de trabalho, para que possam, com isso, aumentar a quantidade de cana que cortam por dia e obter um acréscimo em seu salário, o que é bastante vantajoso para as usinas, as maiores interessadas no aumento crescente da produtividade de seus trabalhadores.

Importa ressaltar, ainda, que o pagamento por produção tem sido identificado por alguns pesquisadores como uma das principais causas das doenças ocupacionais, das mutilações, dos acidentes de trabalho e até mesmo das mortes de trabalhadores rurais (Alves, 2006). Pelo fato de receberem de acordo com sua produtividade individual e desconhecerem ao certo a quantidade de cana que cortam por $\mathrm{dia}^{12}$, os trabalhadores rurais convivem diariamente com a inse-

\footnotetext{
${ }^{12}$ Este desconhecimento da quantidade de cana que cortam por dia está diretamente ligado ao fato de os cortadores de cana estarem sujeitos a sistemas de medição e pesagem da cana que foram desenvolvidos pelos departamentos agrícolas das usinas com o intuito de confundi-los e ludibriá-los: os trabalhadores rurais cortam cana durante toda a sua jornada de trabalho. Após terminarem, esta é medida em metros. Entretanto, o salário que receberão terá como base o peso da cana cortada (me-
} 
gurança de não saber previamente o valor que irão receber por um dia de trabalho. Nesse contexto, não são raras as ocasiões em que muitos trabalhadores se empenham mais do que o suportável para cortar uma quantidade cada vez maior de cana, podendo, assim, vir a se machucar e a se lesionar seriamente. Segundo o Serviço Pastoral dos Migrantes (SPM), entre as safras de 2003/04 e 2007/2008, vinte e um cortadores de cana morreram em decorrência do excesso de trabalho nos canaviais paulistas.

\section{CONSIDERAÇÕES FINAIS}

$\mathrm{O}$ presente artigo buscou analisar alguns aspectos gerais das condições de vida e de trabalho dos cortadores de cana brasileiros. Esse exercício se faz importante e necessário em função não somente da pouca visibilidade que tais trabalhadores têm na sociedade como um todo, mas principalmente porque os assalariados rurais têm sido cada vez menos estudados até mesmo pelos pesquisadores acadêmicos brasileiros.

Além de apresentar aos leitores quem são esses homens que vão trabalhar nas mais diversas usinas de açúcar e álcool do Brasil, a primeira parte deste artigo analisou os motivos que levam esses trabalhadores a buscar emprego assalariado em outras regiões, que não suas regiões de origem. Como visto, na maioria dos casos, esses homens se encontram destituídos de meios reais de sobrevivência em sua terra natal e, por isso, acabam procurando trabalho nas usinas por ser essa uma atividade que lhes assegura algum tipo de renda e, consequentemente, a sobrevivência de si e de suas famílias.

Ao longo dos meses em que estão trabalhando fora, a maior parte dos cortadores de cana envia mensalmente parte do que recebe para seu grupo doméstico que permaneceu no norte, que, na maioria dos casos, conta somente com os parcos recursos advindos dos pro-

dido em toneladas). Essa remuneração dos trabalhadores tendo como base o peso (toneladas) e não o metro é extremamente importante para as usinas, já que, se remunerassem seus empregados por metro, os usineiros estariam assegurando-lhes uma maior autonomia, já que os trabalhadores teriam condições de controlarem o resultado do seu trabalho (Alves, 1991). Ao remunerar os cortadores de cana tendo como base a tonelada, as usinas buscam impedir que os trabalhadores saibam a exata quantidade de cana que cortaram, o que facilita que as empresas roubem seus empregados, pagando um salário que não condiz com a quantidade de cana que de fato cortaram. 
gramas federais de transferência de renda. Assim, é por intermédio dessa quantia que as famílias podem adquirir os insumos necessários à sua sobrevivência e à sua reprodução. Já a partir do momento em que retornam à sua região de origem, parcela significativa do que os cortadores de cana conseguiram poupar ao longo dos meses em que trabalharam nas usinas é investida, em sua própria terra natal, na compra de bens materiais, de terrenos e de animais de criação, na reforma da casa, etc. É por isso que o dinheiro da cana é tão valorizado por esses trabalhadores rurais, que, por seu intermédio, passam a ter um padrão de consumo diferenciado do que tinham antes de migrar.

O foco do artigo passa a ser outro na segunda seção. Nessa parte, a análise é deslocada dos lugares de origem para os lugares de destino dos cortadores de cana, e são as condições de trabalho desses homens e as dificuldades enfrentadas por eles para se manterem em seu emprego e para conseguirem juntar algum dinheiro que passam a ser o objeto de investigação. Verificou-se que o setor sucroalcooleiro como um todo lança mão dos mais diversos tipos de estratégias que são desenvolvidas especialmente para as usinas obterem um controle cada vez maior dos cortadores de cana e dos resultados de sua produção, fator imprescindível para que consigam aumentar seus lucros e seu capital.

Nesse contexto, muitos fatores entram em cena: a imposição de metas de produtividade diárias a serem atingidas pelos trabalhadores, os mecanismos de pressão criados para controlá-los e discipliná-los cada vez mais, os treinamentos e os PPR's (que visam motivá-los e envolvê-los na perseguição dos objetivos das usinas), os prêmios que são concedidos somente aos trabalhadores mais produtivos e que são utilizados como um estímulo concreto para elevar a produtividade dos trabalhadores rurais, o pagamento por produção (forma de remuneração que impede que os cortadores de cana adquiram o controle de seu processo de trabalho e de seu pagamento) etc. Tudo isso compõe o cenário encontrado por esses trabalhadores ao chegarem às usinas e fará parte de seu cotidiano durante todos os meses da safra. 


\section{REFERÊNCIAS}

ADISSI, P. J.; SPAGNUL, W. Convenções coletivas: quantificando o roubo dos patrões. Proposta. Vol. 14, n42, pp. 47-52, 1989.

ALVES, F. J. da C. Modernização da agricultura e sindicalismo: lutas dos trabalhadores assalariados rurais na região de Ribeirão Preto. 1991. Tese (Doutorado em Economia). Programa de Pós-graduação em Economia, Universidade Estadual de Campinas, Campinas, 347 p.

. Por que morrem os cortadores de cana? Saúde e Sociedade. Vol. 15, n³, pp. 90-98, 2006.

. Trabalho e trabalhadores no corte de cana: ainda a polêmica sobre o pagamento por produção e as mortes por excesso de trabalho. In: BISON, Nelson; PEREIRA, José Carlos Alves (Orgs.). Agrocombustíveis, solução? A vida por um fio no eito dos canaviais. São Paulo: CCJ, 2008. (pp. 22-48).

DURHAM, E. A caminho da cidade. A vida rural e a migração para São Paulo. São Paulo: Ed. Perspectiva, 1984.

- As comunidades rurais tradicionais e a migração. In: THOMAZ, Omar Ribeiro (Org.). A dinâmica da cultura. São Paulo: CosacNaify, 2004. (pp. 133-180).

. Migrantes rurais. In: THOMAZ, Omar Ribeiro (Org.). A dinâmica da cultura. São Paulo: CosacNaify, 2004. (pp. 183-201).

GARCIA Jr., A. R. O Sul: caminho do roçado: estratégias de reprodução camponesa e transformação social. São Paulo: Marco Zero; Brasília, DF: Editora da Universidade de Brasília: MCT-CNPq, 1989.

GUANAIS, J. B. No eito da cana, a quadra é fechada: estratégias de dominação e resistência entre patrões e cortadores de cana em Cosmópolis-SP. 2010. Dissertação (Mestrado em Sociologia). Programa de Pós-graduação em Sociologia, Universidade Estadual de Campinas, Campinas, SP, 232 p.

KREIN, J. D. Reforma do sistema de relações de trabalho no Brasil. In: DIEESE; CESIT (Orgs.). Emprego e desenvolvimento tecnológico. São Paulo: DIEESE; Campinas: CESIT, 1999. (pp. 260 - 281).

MARX, Karl. O Capital: Crítica da Economia Política. São Paulo: Boitempo, 2013. MENEZES, M. A. de. Redes e enredos nas trilhas dos migrantes: Um 
estudo de famílias de camponeses-migrantes. Rio de Janeiro: Relume Dumará; João Pessoa, PB: EDUF, 2002.

NOGUEIRA, V.S. “Sairpelomundo”: a conformação de uma territorialidadecamponesa. 2010. Tese (Doutorado em Antropologia). Programa de Pós-graduação em Antropologia Social, Universidade Estadual de Campinas, Campinas, 280 p.

NOVAES, J. R. P. Dores e febres nos canaviais paulistas. Revista Estudos Avançados. 21 (59), pp. 167-177, $2007 \mathrm{a}$.

. Heróis anônimos. Democracia viva. N 36, pp. 58-67, 2007 b.

PAIXÃO, M. J. de P. No coração do canavial: estudo crítico da evolução do Complexo Agroindustrial Sucro-alcooleiro e das relações de trabalho na lavoura canavieira (estudo comparativo em 12 estados do Brasil. 1994. Dissertação (Mestrado em Engenharia de Produção). Programa de Pós-graduação em Engenharia de Produção, Universidade Federal do Rio de Janeiro, Rio de Janeiro, 203 p.

PRADO, M. L. Flexibilização e novas estratégias de intensificação do trabalho nas usinas de açúcar e álcool a partir dos anos 90. Estudo de caso na região de Ribeirão Preto, São Paulo, Brasil. 2008. Dissertação (Mestrado em Sociologia). Programa de Pós-graduação em Sociologia, Universidade Estadual Paulista, Araraquara, 125 p.

SCOPINHO, R. A. Qualidade Total, saúde e trabalho: uma análise em empresas sucroalcooleiras paulistas. RAC. Vol.4, nº.1, pp. 93-112, 2000.

SIGAUD, L. Os clandestinos e os direitos: estudo sobre os trabalhadores da cana-de-açúcar de Pernambuco. São Paulo: Duas Cidades, 1979.

SILVA, M. A. de M. Errantes do fim do século. São Paulo: Ed. Unesp, 1999. - Trabalho e trabalhadores na região do "mar de cana e do. rio de álcool”. RELET - Revista latinoamericana de estúdios del trabajo. No 17, pp. 48-69, 2005.

. A morte ronda os canaviais paulistas. Revista da Associação Brasileira de Reforma Agrária. Vol.33, n², pp. 111-114, 2006.

THOMAZ Jr., A. Por trás dos canaviais os “nós” da cana: a relação capital x trabalho e o movimento sindical dos trabalhadores na agroindústria canavieira paulista. São Paulo: Annablume/Fapesp, 2002.

Recebido: 25/04/2014.

Aprovado: 15/06/2014. 